\title{
Research on the Interconnected River System Network of Three Lakes and One River in Guiyang
}

\author{
Zhang Dan*, Guo Zuo-qing**, Yang Hui-xia***† and Liang Li**** \\ *Civil Engineering College, Guizhou University, Guiyang 550025, China \\ **The Yangtze River Water Resources Committee of Yangtze River Project Supervision Consulting Co. Ltd. (Hubei), \\ Wuhan 430014, China \\ ****ivil Engineering College, Guizhou University, Guiyang 550025, China \\ ****Guizhou Provincial Water Conservancy Research Institute, Guiyang, 550025, China \\ $\dagger$ Corresponding author: Yang Hui-xia; bt-yanghuixia@163.com
}

Nat. Env. \& Poll. Tech. Website: www.neptjournal.com

Received: $15-05-2020$

Revised: 22-06-2020

Accepted: 16-07-2020

Key Words:

River system network

Karst

River

Lakes

\begin{abstract}
The main geological landform in southwest China is karst, and hydrological resources in the region are rich. The water resources in this region cannot be efficiently and rationally used due to the complex topography and difficulty in developing water resources, which has led to problems such as desertification and soil erosion. The most typical area of karst landforms is in Guizhou Province. A water management method for an interconnected river system network is proposed, taking Guiyang as an example. This study provides a foundation for China's South-to-North Water Diversion Project and can improve socioeconomic conditions in China.
\end{abstract}

\section{INTRODUCTION}

Currently, human activities are becoming increasingly intense. With the rapid development of science and the economy, our living standards have significantly improved. However, we have encountered problems related to sustainable development. The territory of China covers 9.6 million square kilometres, which has many advantages and encompasses large quantities of land and natural resources. However, these resources are not evenly distributed in space. For example, the water resources in southeast China account for $46 \%$ of the national water resources and $84 \%$ of the water resources in the entire western part of the country. Hydropower resources could account for $75.6 \%$ of the resources in western regions (Zhang et al. 2004), but the utilization rate is 6\%. The problems in the southwest region are related to the ruggedness, vulnerability of the ecological system, low environmental capacity and inability to withstand natural disasters, which have led to difficulty in the development of water resources in karst areas.

An interconnected river system network (IRSN) is an important part of the land -water system, and it has been considered in national water resource management. From the perspective of biodiversity, the connected rivers have more species than the disconnected rivers (Jiang et al. 2020), Moreover, it is important for the river with good connectivity in hydrodynamics (Phillips et al. 2011). In hydraulic, storage thresholds at a range of scales have now been recognized as important, connectivity has become an important concept crucial to understanding how water is transferred through a catchment (Spence 2010), IRSNs provide a solution for repairing and adjusting existing water system patterns by connecting the hydraulic relationships among adjacent reservoirs and mitigating the uneven geographical distribution of water ( $\mathrm{Li}$ et al. 2011a). This can also provide a solution for rivers about increasing the utilization rate and securing sustainable ability (Xu et al. 2011). Wu et al. (2007) proposed IRSNs could be used as the indexes of river health. Therefore, IRSNs are of great significance to the redistribution of water resources in karst areas.

\section{GLOBAL RESEARCH STATUS OF IRSNS}

Most of the IRSN projects connect the disconnected water with some new hydraulic works. There are various IRSN projects in some western countries, such as Nile irrigation project in ancient Egypt, Central Valley Project in the United States and Garrison Water Diversion Project in the United States (Cui et al. 2011). Many scholars have researched on connected river network; Vannote et al. (1979) put forward the river continuum concept, and the implications of the con- 
cept in the areas of structure, function, and stability of riverine ecosystems are discussed. Amoros et al. (1988) proposed the interactions between water bodies within the floodplains of large rivers. Ward et al. (1989) proposed the four-dimensional framework in natural lotic ecosystems. Pringle (2001, 2003) had further research, which is the understanding of how the river networks are affected by hydrologic alterations that originate outside of their boundaries. He originally proposed that the calculation of river is at a regional scale or a global scale. In China, the research on IRSNs is relatively recent, and IRSN projects in many areas are in the initial stage. IRSN projects can not only improve the uneven distribution of water resources but also improve the ecological environment and promote socioeconomic benefits. Therefore, many scholars have performed studies on this topic. At the beginning of the 21 st century, some scholars began to pay attention to assessing river health. Dong (2005) conducted physical-chemical and biological habitat quality assessments. According to the relevant evaluation criteria for river health, Zhang et al. (2010) analysed the influence of water system connectivity on the Yangtze River in 2010 with three criteria and concluded that water system connectivity has an obvious optimization effect on the ecological environment. Li et al. (2011b), who started from conceptual analysis and proposed a corresponding classification system, performed an in-depth study of a connected water system of rivers and lakes. Later, some Chinese scholars discussed and studied IRSNs in specific cities. For example, Zheng (2017) proposed the IRSN for Shenyang, which involved one district, three corridors, five channels and 20 wetlands. Wang (2017) is planning an IRSN in Taiyuan that includes one lake, nine rivers, dual water diversion sources, and four river and lake connectors.

\section{CHINESE IRSN PROJECTS}

As a new approach to solving urban water resource problems, IRSN projects in China have been implemented in most cities. Many cities have started to create IRSN projects to address existing water resource problems. The IRSN projects in some cities are summarized in Table 1.

The IRSN project mechanisms are not yet fully understood and must be assessed from practice, so further studies of IRSNs are necessary; moreover, such projects still have many problems to be solved. Still, IRSN projects have relatively great prospects for development.

\section{WATER DISTRIBUTION AND THE PROBLEMS IN GUIYANG}

Guiyang's location is in the central part of Guizhou Province and east of the Yunnan-Guizhou Plateau; the terrain in this area is high in the southwest and low in the northeast, and
Table 1: Some domestic IRSN projects.

\begin{tabular}{|lll|}
\hline Project Site & IRSN Project Name & Project Status \\
\hline Chongqing & Bibei River to Binan River & Plan to use in 2020 \\
Changsha & Dazhongyuan River & Plan to use in 2020 \\
Xining & $\begin{array}{l}\text { Xigan Channel, Guosi Chan- } \\
\text { nel, and Jiefang Channel }\end{array}$ & $\begin{array}{l}\text { Finished 60\% at the } \\
\text { beginning of 2019 }\end{array}$ \\
Huanggang & Changhe River & Started in 2019 \\
Jiujiang & Bali Lake, Saicheng Lake & Started in 2019 \\
Dazhou & Xi Bridge to Mingyue & Started in 2017 \\
& Bridge & \\
Mudanjiang & Main river in the city & Started in 2016 \\
\hline
\end{tabular}

there is a main mountainous and hilly landscape (Wang et al. 2015). The mountain area totals 4218 square kilometres, level areas encompass only 912 square kilometres, and canyon areas account for $1.2 \%$ of Guiyang. The average annual rainfall in the area is $1129.5 \mathrm{~mm}$, and this rainfall feeds the Wujiang River in the Yangtze Basin and the Hongshui River in the Zhujiang Basin, of which the former is larger. The water flow in Guiyang is very complicated, and the water resources are mainly from rain. According to statistics, there are approximately 98 rivers in Guiyang, including 90 rivers in the Yangtze Basin and 8 rivers in the Zhujiang Basin. Additionally, Hongfeng Lake, Baihua Lake, Aha Lake and Huaxi Reservoir are the main surface waters. According to the Water Resources Bulletin in Guiyang, the water resource volume is less than that in other cities, and the frequency of dry years is high, so the water resource reserves require specific attention. Besides, the proportion of surface water resources accounts for one-third of the total, as given in Table 2.

\section{Problems with Water Resources in Guiyang}

Guiyang has a large number of water resources, but these resources are difficult to effectively utilize. Therefore, Guiyang has the same water problems as many large and medium-sized cities, and the specific water shortage problems are as follows:

Table 2: Water resources over the years in Guiyang.

\begin{tabular}{|c|c|c|c|c|}
\hline Year & $\begin{array}{l}\text { Total Water } \\
\text { Resources } \\
\left(10^{12} \mathrm{~m}^{3}\right)\end{array}$ & $\begin{array}{l}\text { Groundwater } \\
\text { Resources } \\
\left(10^{12} \mathrm{~m}^{3}\right)\end{array}$ & $\begin{array}{l}\text { Proportion } \\
(\%)\end{array}$ & $\begin{array}{l}\text { Level of } \\
\text { Runoff }\end{array}$ \\
\hline 2013 & 33.58 & 11.97 & 35.6 & Dry stage \\
\hline 2014 & 58.09 & 14.4 & 24.8 & $\begin{array}{l}\text { Abundant } \\
\text { stage }\end{array}$ \\
\hline 2015 & 48.28 & 13.58 & 28.1 & Normal stage \\
\hline 2016 & 32.55 & 9.96 & 30.6 & Dry stage \\
\hline 2017 & 52.65 & 13.78 & 26.2 & $\begin{array}{l}\text { Abundant } \\
\text { stage }\end{array}$ \\
\hline
\end{tabular}


1. General water shortage - the annual rainfall is limited from November to March in the subsequent year, and there are no major floods even during the flood season in summer.

2. Engineering water shortage - the site is located near the sources of many rivers near, but also the centre of the karst belt. The karst landform is permeable and has a large altitude gradient. As a result, it is difficult to build hydraulic structures in the area, and most precipitation runs off.

3. Ecological water shortage - as in many cities, agriculture and industry are developing rapidly in Guiyang. However, the drainage of industrial water is not properly regulated, which has led to pollution and the destruction of water sources in the city.

4. Geological water shortage - there is the typical karst landform in Guiyang, so the ecological environment is vulnerable. In addition, mountains divide the water system, which makes the hydrological connectivity poor. Moreover, the strong permeability enriches groundwater resources, reduces the amount of surface water and decrease the total volume of usable water resources.

\section{Main Solutions}

Resource water shortage: Due to the lack of precipitation and accessible water, water consumption should be controlled to ensure that sufficient water is available. Urban water resources mainly come from rainfall and rivers. However, the precipitation varies based on the geographical location and climatic environment, and water mainly comes from rainfall; thus, urban rainfall is very difficult to collect and use, and water must be reasonably conserved.

1. Urban water: Residents' awareness regarding water saving must be enhanced. Earth's resources are not inexhaustible, and we must rationally use resources to obtain long-term benefit. The public must be informed about the importance of water savings and the effects of water issues on everyday life.

2. Industrial water: We must emphasize using water reasonably and standardizing wastewater treatment. Industrial water is more treatable than urban water, so the potential effect of saving industrial water is greater. Moreover, industrial wastewater can be recycled. We should reuse water as much as possible to alleviate the problem of insufficient resources.

Engineering water shortage: Because the construction of large-scale hydraulic engineering projects generally requires considerable land resources, there are no large hydro- junctions in the city. The large and medium-sized reservoirs in Guiyang are listed as follows (large and medium-sized reservoirs have a capacity of 10 million cubic meters to 1 billion cubic meters): Aha Lake, Hongfeng Lake, Huaxi Reservoir, Baihua Lake. The details are as in Table 3.

Thus, the large and medium-sized reservoirs are mainly concentrated in the west and south of the city, and there are relatively few water-retaining structures in the eastern area, so the water transport is from the west to the middle and eastern parts of the city. According to the water system conditions, an appropriate water-retaining structure should be built in the eastern part of the city to supply water in multiple directions, thus creating a balanced conveyance network.

Ecological water shortage: For this problem, the level of industrial wastewater generation should be standardized. Heavy polluters, such as Guigang industry, moved out of the city in 2013, but the manufacturing processes resulted in inevitable pollution. In addition, the discharge of polluted wastewater was common. In 2017, Zhongtieyueshan Lake was polluted by construction wastewater from Wanda and resulted in fish death on a large scale. Because of vigorous urban development, many industries have ignored the problem of sewage discharge. Therefore, promoting the management of wastewater and the relevant laws and regulations could curb water source pollution by sewage in a timely manner.

Geological water shortage: Guiyang is a typical region with many karst phenomena. In karst areas, the soil permeability is high, and the groundwater volume is large; this volume mainly comes from surface water seepage and atmospheric precipitation. From a geomorphological perspective, the karst geomorphology accounts for $83 \%$ of the whole city.

1. We can increase groundwater use to reduce the consumption of surface water.

2. For facilities that need to collect water, such as artificial lakes in urban areas, to supply water for residents and other domestic water uses, artificial impervious membranes can be adopted; such measures can greatly improve the utilization rate of surface water resources and reduce underground seepage in karst areas.

Table 3: Three lakes and one river in Guiyang.

\begin{tabular}{|llll|}
\hline Reservoir name & $\begin{array}{l}\text { Capacity } \\
\left(10^{4} \mathrm{~m}^{3}\right)\end{array}$ & $\begin{array}{l}\text { Basin } \\
\text { area } \\
\left(\mathrm{km}^{2}\right)\end{array}$ & $\begin{array}{l}\text { Location } \\
\text { (Relative to the } \\
\text { Downtown Area) }\end{array}$ \\
\hline Aha Lake & 8658 & 190 & Southwestern \\
Huaxi Reservoir & 3140 & 325 & South \\
Hongfeng Lake & 60000 & 1551 & Western \\
Baihua Lake & 19100 & 1831 & Northwestern \\
\hline
\end{tabular}




\section{PROPOSAL OF AN IRSN PROJECT IN GUIYANG}

Karst is a special landform that is mainly composed of carbonate rocks; the soil is slightly alkaline, and carbonate minerals are highly soluble, so they are not easily weathered. As a result, the soil layer in karst areas is thin and is characterised by poor water storage. With barren land and severe calcification, only some plants, such as alkaline plants, can survive in karst areas (Yang 1990). A causality diagram of karst ecosystem sensitivity is provided in Fig. 1. Establishing a reasonable and effective IRSN project can improve the soil ecological environment. The aim of governing the current channels and building a new channel is to strengthen the water area connectivity and improve water quality.

\section{Developing the IRSN Project}

The thin soil layer: Areas with good soil quality can provide sufficient nutrients for vegetation growth and reduce soil and water loss during torrential rainfall events. According to the soil properties in karst areas, the thickness of the weathered soil layer is inversely proportional to the erosion rate of the weathered rock. For the farmland in Guiyang, high nutrient levels are needed to support the growth of the crops, so fertilizer in the soil, such as green manure, is needed to increase the mineral content. Besides, ecological slope protection measures should be implemented to reduce landslides, which can also promote the restoration of the ecological system, create good river ecosystems, and improve the ecological environment in the city.

Weak resistance to disaster: There are abundant groundwater resources in Guiyang, and the water storage capability of the soil is poor; thus, it is necessary to enhance the connection between surface water and groundwater. Surface pollutants will seep into the groundwater due to the high permeability of the karst, leading to groundwater pollution, low oxygen concentrations, scarce microorganisms and a poor self-purification capacity. Therefore, we can appropriately increase the number of sewage treatment plants and improve urban wastewater discharge management. For example, the regulation project of the Nanming River in Guiyang is a typical water decontamination project. In addition, it is important to improve water quality by testing the upstream water quality in Hongfeng Lake and Baihua Lake; only when we do this can we mitigate the pollution at the source to improve the water quality in the city and create a healthy and liveable ecological environment.

Based on the ArcGIS, Fig. 2 shows the general distribution of the water system and the variations in the terrain elevation in Guiyang (this paper mainly discusses the area circled in red). The main waters are Hongfeng Lake, Baihua Lake, Aha Lake and Huaxi Reservoir. The four lakes supply seven residential areas (Yunyan district, Nanming district, Wudang district, Guanshanhu district, Baiyun district, Huaxi district and Qingzhen). The reason for the high water conveyance pressure is the long distance between the centralized and regional water conveyance channels. With reference to channel in California, United States, we can build a channel that transports water from the northwestern to southeastern parts of the city and provides water to water-deficient areas such as Wudang district and densely populated areas of Nanming and Yunyan districts. Otherwise, the natural landform leads to abundant resources in the west but limited in the east, we could develop an underground water storage location in the west to mitigate water shortage issues in the dry season.

\section{CONCLUSION}

In China, Guiyang is a typical city with regional karst landforms; the area is characterised by abundant hydropower resources and low usage rates. The hydrology in karst

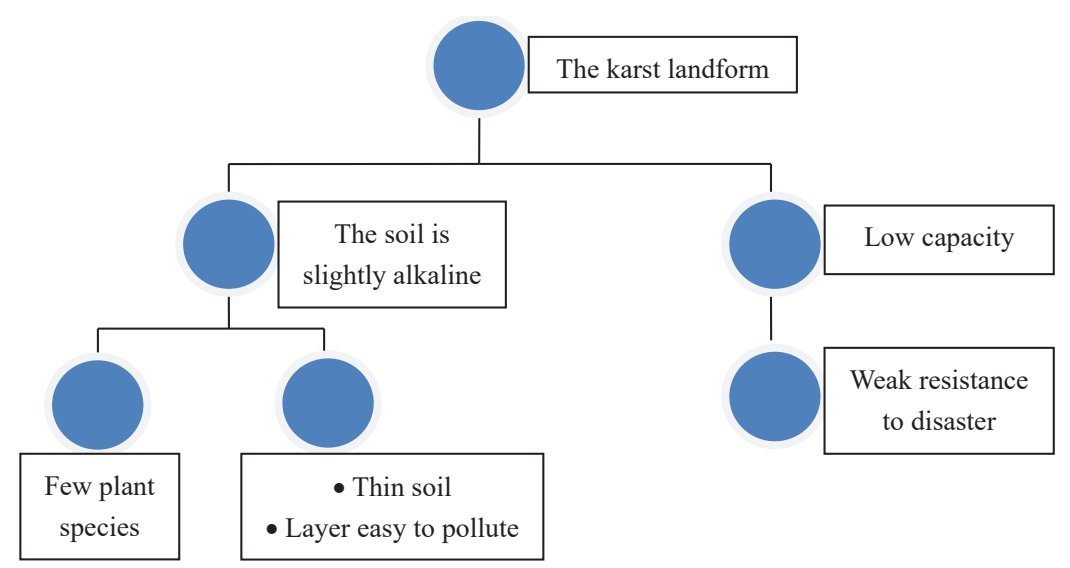

Fig. 1: A causality diagram of karst ecosystem sensitivity. 


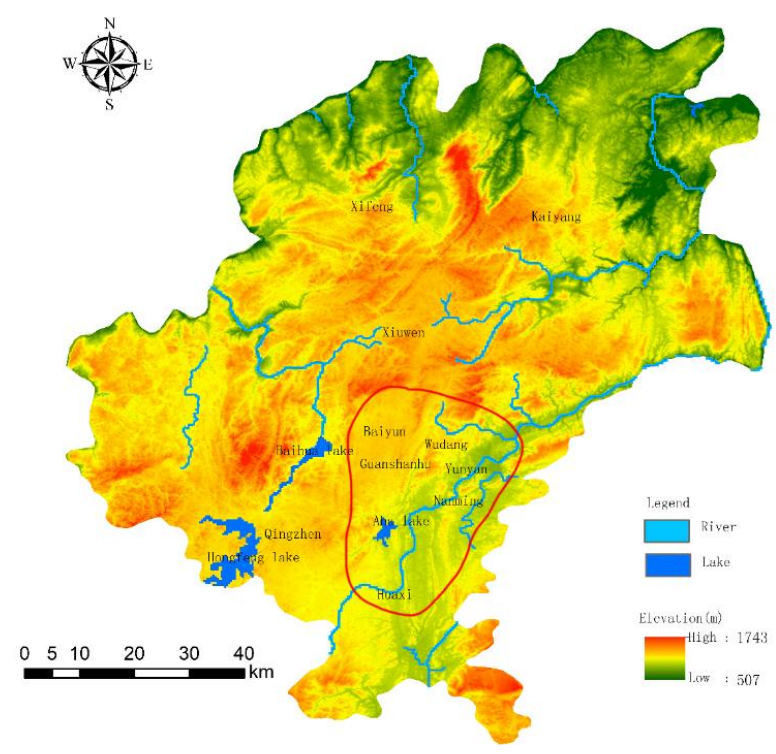

Fig. 2: Water system and geological map of Guiyang.

areas can lead to water conservancy issues. This paper first addresses the basic reasons for the lack of available water resources in the city.

1. Engineering water shortages

2. General water shortages

3. Ecological water shortages

4. Geological water shortage

Based on an IRSN project, this paper proposes a method to solve the water resources issues in Guiyang. If the water resource problem in karst areas can be effectively solved, the utilization rate of water resources in Southwest China can be greatly improved, which can contribute to a national water resource balance and generate great social benefits.

\section{ACKNOWLEDGEMENT}

The article is supported by: (1) Young Talents Project of Guizhou Provincial Department of Education [Grant No.KY (2017) 120] and (2) The Special Foundation of the Water Conservancy Bureau of Guizhou Province (Grant No. KT201712)

\section{REFERENCES}

Amoros, C. and Roux, A.L. 1988. Interactions between water bodies within floodplains of large rivers: function and development of connectivity. Muensterische eographische Arbeit, Muenster, 1988: 125-130.

Cui, G.T., Zuo, Q.T. and Dou, M. 2011. Development evolution and influences of the interconnected river system network at home and abroad. South-toNorth Water Diversion and Water Science \& Technology, 9(4): 73-76.

Dong, Z.R. 2005. Principles and methods of river health assessment, China Water Resources, 10: 17-19.

Jiang, X.M., Pan, B.Z., Sun, Z.W., Cao, L. and Lu, Y. 2020. Application of taxonomic distinctness indices of fish assemblages for assessing effects of river-lake disconnection and eutrophication in floodplain lakes. Ecol. Indic., 110: 105955.

Li, Z.L., Li, Y.Y., Wang, Z.G., Hao, X.P. and Liu, X.J. 2011a. Research on interconnected river system network: Conceptual framework. Journal of Natural Resources. 26(03): 513-522.

Li, Z.L., Hao, X.P., Wang, Z.G., Liu, X.J. and Li, H. 2011b. Exploration on classification of interconnected river system network. Journal of Natural Resources, 26(11): 1975-1982.

Phillips, R.W., Spence, C. and Pomeroy, J.W. 2011. Connectivity and run off dynamics in heterogeneous basins. Hydrological Processes, 25: 3061-3075.

Pringle, C.M. 2001. Hydrologic connectivity and the management of biological reserves: A global perspective. Ecological Applications, 11: 981-998.

Pringle, C.M. 2003. What is hydrologic connectivity and why is it ecologically important. Hydrological Progresses, 17(13): 2685-2689.

Spence, C. 2010. A paradigm shift in hydrology: Storage thresholds across scales influence catchment runoff generation. Geography Compass, 4/7: 819-833.

Vannote, R.L., Minshall, G.W., Cummins, K.W., Sedell, J.R. and Cushing, C.E. 1980. The river continuum concept. Canadian Journal of Fisheries and Aquatic Sciences, 1980: 130-136.

Wang, J.J. 2017. Research on urban design for quality improvement in the new era. Shanxi Architecture, 43(36): 18-20.

Wang, S.J., Zhang, X.B. and Bai, X.Y. 2015. An outline of karst geomorphology zoning in the karst areas of southern China, Mountain Research, 33(06): 641-648.

Ward, J.V. 1989. The four-dimensional nature of lotic ecosystems. Society for Freshwater Science Stable, 8(1): 2-8.

Wu, D.X. and Huang, S.P. 2007. Study on the index system of healthy Yangtze River, Express Water Resources \& Hydropower Information, 28(12): 1-3.

Xu, Z.X. and Pang, B. 2011. Cognition scientifically of river and lake systems interconnection. China Water Resources, 16: 13-16.

Yang, M.D. 1990. On the fragile of karst environment. Yunnan Geographic Environment Research, 2(01): 21-29.

Zhang, L.Q. and Chen, Y. 2004. The Management of water resources in southwestern region of China. Resource Development \& Market, 6: 421-423.

Zhang, O.Y., Pu, H.F., Wang, C.P. and Xiong, M. 2010. Impact of drainage connectivity on river health in Yangtze River Basin. Yangtze River, 41(2): 1-5+17.

Zheng, H. 2017. Planning of river-lake network project in Shenyang City. China Water Resources, 11: 52-53+13. 